23

\title{
Особенности построения люминесцентного микроскопа для изучения эпителио-мезенхимальной трансформации клеток in vitro
}

\author{
(C) К.А. Фомичева ${ }^{1}$, О.В. Киндеева ${ }^{2,3 \mp}$, В.А. Петров ${ }^{2,3}$, А.А. Иванов ${ }^{2,4}$, А.А. Полозников ${ }^{2}$ \\ Б.Я. Алексеев ${ }^{1}$, М.Ю. Шкурников ${ }^{1}$ \\ ${ }^{1}$ ФГБУ „НМИЦ радиологии“ Минздрава России, \\ 125284 Москва, Россия \\ ${ }^{2}$ НТЦ „БиоКлиникум“, \\ 115088 Москва, Россия \\ 3 „Московский авиационный институт (национальный исследовательский университет)“ \\ 125993 Москва, Россия \\ ${ }^{4}$ Центр фотохимии РАН, \\ 119421 Москва, Россия \\ I e-mail: o.kindeeva@bioclinicum.com
}

Поступила в редакцию 23.11.2017 г.

В окончательной редакции 27.02.2018 г.

\begin{abstract}
Разработан оптический люминесцентный микроскоп для наблюдения за поведением опухолевых клеток, модифицированных флуоресцентными белками GFP и RFP, и регистрации образования метастазов в биочипах. Изображения клеток в свете флуоресценции белков GFP и RFP, а также в режиме фотосъемки фиксируются в микроскопе неохлаждаемой CMOS-матрицей при возбуждении люминесценции синим и зеленым светодиодами и освещении клеток белым светодиодом соответственно. Полученные флуоресцентные изображения и фотографии в белом свете регистрируются матрицей в одной системе координат и не требуют дополнительной обработки для совмещения. Мощность облучения клеток светодиодами не превышает $50 \mu \mathrm{W} / \mathrm{mm}^{2}$ при времени экспозиции одна секунда, что на порядок ниже уровня мощности излучения, вызывающего фоторазрушение и фототоксикацию клеток при проведении длительных исследований. Введены относительные параметры оптического канала люминесцентного микроскопа, позволяющие сравнивать чувствительность системы регистрации и минимальный уровень мощности возбуждающего люминесценцию излучения для оптических элементов с различными спектральными характеристиками.
\end{abstract}

DOI: $10.21883 /$ OS.2018.07.46279.269-17

\section{Введение}

Современные оптические методы исследования живых организмов в биологии и медицине являются эффективными, разнообразными и наименее инвазивными. Тем не менее, их следует с осторожностью использовать при долговременном наблюдении за живыми биологическими объектами, так как мощность и доза светового облучения могут вызывать фотохимические процессы в клетках и их молекулярном окружении, существенным образом изменяя их структуру и развитие [1]. Флуоресцентная микроскопия [2,3] и многофотонная микроскопия $[4,5]$ с успехом используются при диагностике заболеваний кожи. С помощью оптоволоконных зондов проводятся исследования биологических процессов in vivo в тканях животных с применением различных оптических методов [6]. Для клеток многих органов человека проводить такие наблюдения и исследовать влияние лекарственных препаратов невозможно. Альтернативой исследованию клеток человека in vivo являются эксперименты с клеточными моделями в микрофлюидных устройствах $[7,8]$, в которых клетки культивируются в замкнутом объеме. Через ячейки с клеточными моделями прокачивают питательные и лекарственные рас- творы, моделирующие условия существования клеток в живом организме. Для визуализации и исследования процессов трансформации в клетки встраивают белки, обладающие различными оптическими свойствами $[9,10]$, так называемые белковые флуоресцентные метки или флуоресцентные белки. Флуоресцентные белки могут конститутивно экспрессироваться в клетках и сохраняются в них при развитии и размножении. Эта важная особенность флуоресцентных белков позволяет использовать их в качестве флуоресцентных меток для исследования эпителио-мезенхимальной трансформации (ЭМТ) клеток в динамических условиях при внесении в поток питательной среды лекарственных соединений. Внедрение в эпителиальные и мезенхимальные клетки флуоресцентных белков с отличающимися оптическими характеристиками позволяет отслеживать процесс метастазирования в режиме реального времени по сигналам флуоресценции на двух длинах волн, один из которых соответствует эпителиальным клеткам в клеточной модели, а другой - клеткам, трансформировавшимся в мезенхимальный фенотип. Изучение ЭМТ клеток in vitro является сложной задачей, так как инструменты наблюдателя, в данном случае световое излучение, оказывают существенное влияние на объект 
исследования во время достаточно продолжительного процесса трансформации клеток. Наименее инвазивным и безопасным из оптических методов, использующих свет небольшой мощности, является визуальное наблюдение за клетками под микроскопом. Однако только визуальная регистрация процесса ЭМТ не позволяет получить данные обо всех особенностях процесса трансформации клеток, которые можно получить при исследовании с использованием люминесцентных меток. Регистрация изображения клеток по люминесцентному сигналу требует значительного увеличения мощности излучения, освещающего клетки. Это связано с тем, что испускание люминесценции не имеет выделенного направления (молекулы красителя излучают фотоны флуоресценции в $4 \pi \operatorname{sradn})$. Количество фотонов флуоресценции, которые попадают на фотоприемник и формируют изображение клеток, на несколько порядков меньше количества фотонов возбуждающего излучения, так как люминесценция собирается объективом микроскопа в достаточно ограниченном телесном угле. Поэтому в люминесцентном микроскопе при регистрации слабых сигналов от биологических объектов все оптические элементы должны быть подобраны таким образом, чтобы обеспечивать максимальный сигнал люминесценции на фотоприемнике при минимальном уровне мощности излучения, возбуждающего люминесценцию. Оптимизация элементов оптической схемы необходима также для увеличения чувствительности люминесцентного микроскопа с целью обеспечения регистрации клеток при малой концентрации в них флуоресцентных белков.

Целью настоящей работы является разработка микроскопа для проведения исследований процесса ЭМТ в режиме реального времени in vitro. Подобные исследования возможны при регистрации изображения клеток по сигналу люминесценции на двух длинах волн, а также регистрации фотоснимков клеток в белом свете. Изображение клеток по сигналу люминесценции позволяет определить их принадлежность к определенному фенотипу, но не дает визуальную картинку, важную для исследования. Это связано с тем, что испускание люминесценции происходит из небольшой части клетки, содержащей флуоресцентный белок, а интенсивность люминесценции мала и недостаточна для освещения всей клетки и получения изображения в режиме фотосъемки. Регистрация изображения клеток в белом свете позволяет видеть границы клеток и их структуру. Правильный выбор оптических элементов схемы микроскопа, при котором достаточно информативная картина процесса ЭМТ клеток получается при минимальных уровнях мощности излучения, возбуждающего люминесценцию, необходим также, чтобы снизить дозу светового облучения клеток при проведении продолжительных экспериментов в термостатированном биочипе. По возможности конструкция микроскопа должна обеспечивать единую пространственную привязку изображений клеток в режиме фотосъемки и в свете люминесценции для упрощения совмещения всех изображений в одной системе координат.

\section{Оптическая схема люминесцентного микроскопа}

Оптическая схема стандартного люминесцентного микроскопа включает источник излучения, возбуждающего люминесценцию, фотоприемник сигнала люминесценции, оптические фильтры, линзы и зеркала, формирующие спектры и световые потоки возбуждающего излучения в плоскости объекта исследования и флуоресценции в плоскости фотоприемника. Спектральная перестройка возбуждающего излучения, как правило, обеспечивается набором сменных оптических фильтров и источником света с широким спектром излучения [11]. Если микроскоп рассчитан на работу с конкретными красителями, то в качестве источников излучения для возбуждения флуоресценции используют лазеры или мощные светодиоды со сравнительно узкой спектральной полосой излучения возбуждения [12], чтобы обеспечить высокий уровень мощности возбуждающего излучения и регистрацию флуоресценции при минимальных концентрациях красителя.

В настоящей работе спектральные характеристики возбуждающего излучения и люминесценции определены спектрами поглощения и флуоресценции белков GFP и RFP, а уровни сигналов возбуждения и люминесценции заданы концентрацией молекул красителя в клетке. Фотоприемник микроскопа должен видеть отдельные клетки и в совокупности с оптической системой микроскопа регистрировать сигнал люминесценции от молекул красителя в одной клетке, имеющей характерный размер порядка $20 \mu \mathrm{m}$. Предварительные оценки показывают, что для регистрации сигнала люминесценции одной клетки, содержащей 22000 молекул флуоресцентного белка [13], в качестве фотоприемника можно использовать CCD- или CMOS-камеры при возбуждении флуоресценции излучением светодиодов. Спектральные полосы излучения светодиодов и поглощения соответствующих флуоресцентных белков GFP и RFP сравнимы по величине и перекрываются со спектрами флуоресценции. Использование спектральных фильтров только на эмиссию флуоресценции не обеспечивает необходимого подавления излучения светодиодов на фотоприемнике. Необходимо использовать спектральные фильтры на возбуждающее излучение для уменьшения ширины спектра возбуждения и подавления излучения светодиода в спектральном диапазоне регистрации флуоресценции. Подавление длинноволновой части излучения светодиода необходимо для уменьшения засветки светодиодом фотоприемника в спектральной полосе пропускания фильтра эмиссии люминесценции. В то же время подавление коротковолновой части излучения светодиода необходимо для уменьшения засветки 
светодиодом фотоприемника в коротковолновой области фильтра эмиссии, который имеет в этой части спектра паразитные пики пропускания. Более узкий спектр возбуждающего излучения, получающийся при фильтрации излучения светодиода, обеспечивает более эффективное возбуждение флуоресценции, при котором определенное количество фотонов люминесценции высвечивается при более низком уровне мощности возбуждающего излучения. Это происходит при концентрации энергии возбуждающего излучения в спектральной полосе, совпадающей с максимумом полосы поглощения красителя. Снижение уровня мощности возбуждающего излучения является необходимым условием при работе с живыми клетками и уменьшает уровень засветки фотоприемника.

Коммерчески доступные оптические элементы имеют дискретные спектральные характеристики, и задача оптимизации флуоресцентного микроскопа сводится к выбору светодиодов и фильтров, спектральные характеристики которых обеспечивают максимальный сигнал люминесценции при минимальном уровне возбуждающего излучения и максимальном подавлении сигнала засветки фотоприемника излучением светодиода. В идеальном случае для этого необходимо выполнить три очевидных условия.

1. Достичь максимального количества возбужденных молекул красителя при минимальном уровне мощности возбуждающего излучения, облучающего клетки. Ширина спектра излучения, возбуждающего флуоресценцию, должна быть мала по сравнению с шириной полосы поглощения молекул красителя и совпадать с максимумом спектра возбуждения флуоресценции красителя, который, как правило, совпадает с максимумом спектра поглощения красителя. Коэффициент поглощения красителя для различных спектральных компонент накачки тем меньше, чем дальше они отстоят от максимума спектра поглощения. Поэтому, если сравнивать источники излучения с одинаковой интегральной мощностью, но разной спектральной шириной, возбуждение флуоресценции менее эффективно при накачке широким спектром независимо от формы огибающей спектра возбуждающего излучения.

2. Полоса пропускания фильтра эмиссии должна по возможности максимально перекрывать спектр флуоресценции красителя, чтобы обеспечить регистрацию флуоресценции во всем спектральном диапазоне эмиссии.

3. Спектральные характеристики светодиода, возбуждающего флуоресценцию, и фильтров для возбуждающего излучения и эмиссии должны обеспечивать максимальную дискриминацию сигналов флуоресценции и возбуждающего излучения на фотоприемнике. Это условие играет решающую роль, если речь идет о регистрации достаточно слабого сигнала люминесценции от одной клетки, содержащей небольшое количество молекул красителя, при ограниченной мощности и дозе

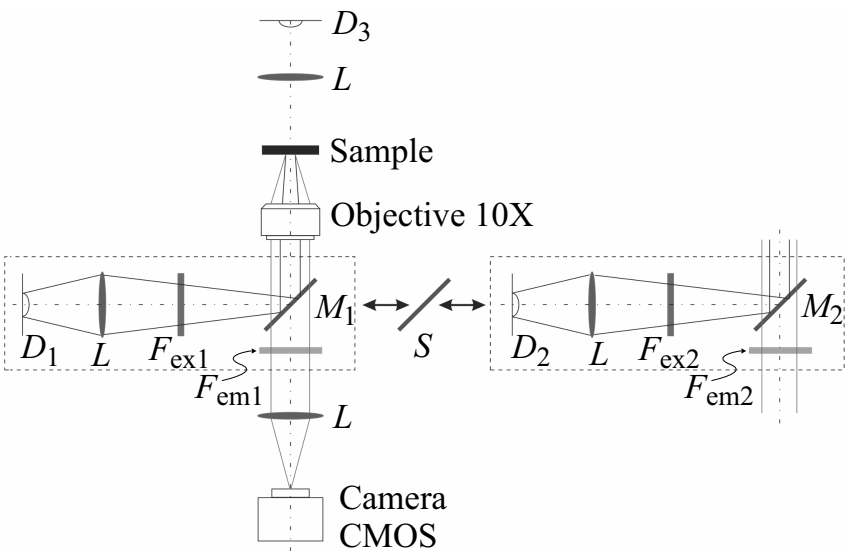

Рис. 1. Оптическая схема флуоресцентного прибора: $D_{1}$, $D_{2}, D_{3}-$ светодиоды; $L-$ оптические линзы; $F_{\mathrm{ex} 1}, F_{\mathrm{ex} 2}-$ светофильтры на возбуждение; $F_{\mathrm{em} 1}, F_{\mathrm{em} 2}-$ светофильтры на эмиссию; $M_{1}, M_{2}$ - дихроичные зеркала; $S$ - плоскопараллельная стеклянная пластинка. Стрелками показана смена световых каналов.

возбуждающего излучения. Это условие трудно выполнить, так как сигнал возбуждающего излучения, пропускаемый фильтрами эмиссии и возбуждения вдали от их основных полос, становится сравнимым по интенсивности с сигналом люминесценции. Характерная ширина по полувысоте спектра светодиодов составляет $20 \mathrm{~nm}$. Примерно на такую же величину отстоят максимумы спектров поглощения и флуоресценции красителей GFP и RFP. Интенсивность светодиода в полосе пропускания фильтра на эмиссию всего в 10-20 раз ниже интенсивности в максимуме спектра излучения светодиода. Поэтому при использовании даже достаточно хороших фильтров на эмиссию и возбуждение с коэффициентом дискриминации $5 \cdot 10^{-6}-10^{-7}$ остаточное пропускание возбуждающего излучения может вносить существенный вклад в сигнал фотоприемника. Именно такая ситуация возникает при регистрации слабой флуоресценции белков GFP и RFP в клетках, возбуждаемой излучением светодиодов.

Оптическая схема флуоресцентного микроскопа (рис. 1) состоит из трех световых каналов. Два флуоресцентных канала предназначены для регистрации сигналов флуоресценции красителей RFP и GFP. Третий канал используется для получения фотографического изображения клеток. На рис. 1 флуоресцентные каналы обведены прямоугольниками из штриховых линий. Светодиоды $D_{1}$ (LTH9GP-JZKZ-26-1-Z Osram) с центральной длиной волны $543 \mathrm{~nm}$ и $D_{2}$ (LBCPDP-GYHY-35 Osram) с центральной длиной волны $470 \mathrm{~nm}$ являются источниками излучения для возбуждения флуоресценции в красителях RFP и GFP соответственно. Светодиод $D_{3}$ (SMA5050) с белым спектром излучения освещает клетки для получения фотографического изображения. Линзы $L$ (LB1187-A Thorlabs) с фокусным расстоянием $40 \mathrm{~mm}$ формируют световое пятно излучения светодио- 
дов $D_{1}, D_{2}$ или $D_{3}$ диаметром $4 \mathrm{~mm}$, освещающее клетки, расположенные в фокальной плоскости объектива ЛОМО 10Х/0.25. Излучение светодиода $D_{1}\left(D_{2}\right)$ после прохождения фильтра $F_{\mathrm{ex} 1}\left(F_{\mathrm{ex} 2}\right)$ отражается дихроичным зеркалом $M_{1}\left(M_{2}\right)$, пропускающим флуоресценцию красителя RFP (GFP). Стеклянная пластинка $S$ вводится в луч светодиода $D_{3}$ при освещении клеток белым светом и смещает изображение клеток в горизонтальной плоскости на такое же расстояние, как зеркала $M_{1}$ и $M_{2}$, так как ее толщина совпадает с толщиной подложек этих зеркал. Светофильтры возбуждающего излучения $F_{\text {ex1 }}$ и $F_{\text {ex2 }}$ в паре с соответствующими фильтрами на испускаемую флуоресценцию $F_{\mathrm{em} 1}, F_{\mathrm{em} 2}$ обеспечивают дискриминацию сигналов возбуждения и флуоресценции на фотоприемнике. Флуоресценция клеток собирается объективом $10 \mathrm{X} / 0.25$, проходит дихроичное зеркало $M_{1}$ $\left(M_{2}\right)$, фильтр эмиссии $F_{\mathrm{em} 1}\left(F_{\mathrm{em} 2}\right)$ и линзой $L$ фокусируется на матрице CMOS-видеокамеры. Оптические элементы двух флуоресцентных каналов и пластинка $S$ расположены на трансляторе, обеспечивающем их перемещение вдоль горизонтальной оси и установку в одно из трех рабочих положений. При смене оптических каналов неточность установки зеркал $M_{1}$ и $M_{2}$ или стеклянной пластинки $S$ вдоль оси трансляции не влияет на положение изображения клеток на матрице фотоприемника. Это позволяет совмещать изображения из разных каналов без дополнительной обработки. Совмещение флуоресцентных изображений и фотографий клеток на матрице фотоприемника в разных оптических каналах достигается первоначальной юстировкой наклона дихроичных зеркал $M_{1}$ и $M_{2}$ и стеклянной пластинки $S$.

\section{Выбор элементов оптической схемы}

Задача оптимизации конструкции микроскопа для каждого флуоресцентного канала сводится к выбору комбинации светодиодов и фильтров, спектральные характеристики которых максимально соответствуют перечисленным выше требованиям. Рассмотрим выбор элементов оптической схемы микроскопа на примере флуоресцентного канала красителя RFP. Зеленые светодиоды фирмы Osram могут иметь центральную длину волны от 513 до $543 \mathrm{~nm}$ и в пределах этого диапазона специфицируются производителем на пять групп (2-6), которые отстоят друг от друга по длинам волн на $6 \mathrm{~nm}$. Для излучения, возбуждающего флуоресценцию красителя RFP, можно использовать фильтры MF525-39, MF530-43, MF535-22, MF542-20, а для эмиссии фильтры MF620-52 и MF630-69 компании Thorlabs. Для отражения возбуждающего излучения и пропускания флуоресценции красителя RFP рассматривалось только одно дихроичное зеркало DMLP567 (Thorlabs), обеспечивающее максимальное разделение излучения возбуждения и люминесценции. Для сравнения различных комбинаций фильтров и светодиодов введен параметр
Таблица 1. Расчетные значения параметров $K$ и $Q$ для различных комбинаций фильтров

\begin{tabular}{c|c|c|c|c|c}
\hline № & LED $\lambda, \mathrm{nm}$ & $F_{\mathrm{ex}}$ & $F_{\mathrm{em}}$ & $\begin{array}{c}K \cdot 10^{-7}, \\
\text { arb. units }\end{array}$ & $\begin{array}{c}Q, \\
\text { arb. units }\end{array}$ \\
\hline 1 & 543 & MF525-39 & MF630-69 & 0.77 & 0.034 \\
2 & 543 & MF525-39 & MF620-52 & 0.58 & 0.034 \\
3 & 543 & MF530-43 & MF630-69 & 0.95 & 0.046 \\
4 & 543 & MF530-43 & MF620-52 & 0.79 & 0.046 \\
5 & 543 & MF542-20 & MF630-69 & 5.99 & 0.04 \\
6 & 543 & MF542-20 & MF620-52 & 4.99 & 0.04 \\
7 & 525 & MF535-22 & MF630-69 & 1.23 & 0.03 \\
8 & 525 & MF530-43 & MF630-69 & 2 & 0.043
\end{tabular}

$K=I_{\ni} / I_{3}$, равный отношению интегрального по спектру сигнала флуоресценции на фотоприемнике $I_{\ni}$ к интегральному по спектру сигналу засветки фотоприемника излучением светодиода $I_{3}$.

Для определения интегрального по спектру сигнала засветки фотоприемника излучением светодиода $I_{3}$ считался интеграл

$$
I_{3}=\int I_{\text {д }}(\lambda) T_{\mathrm{H}}(\lambda) R_{3}(\lambda) T_{3}(\lambda) T_{\ni}(\lambda) d \lambda,
$$

где $I_{\text {д }}(\lambda)-$ спектр излучения светодиода, $T_{\mathrm{H}}(\lambda)-$ спектр пропускания фильтра возбуждающего излучения, $R_{3}(\lambda)$ - спектр отражения дихроичного зеркала, $T_{3}(\lambda)$ - спектр пропускания дихроичного зеркала и $T_{\ni}(\lambda)$ - спектр пропускания фильтра эмиссии.

Интегральный по спектру сигнал флуоресценции на фотоприемнике определялся как

$$
I_{\ni}=Q \int I_{\ni}(\lambda) T_{3}(\lambda) T_{\ni}(\lambda) d \lambda
$$

Здесь $I_{\ni}(\lambda)$ - спектр флуоресценции красителя RFP, $T_{3}(\lambda)$ - спектр пропускания дихроичного зеркала, $T_{\ni}(\lambda)$ - спектр пропускания фильтра эмиссии. Интегральные по спектру сигналы флуоресценции $I_{\ni}$ и засветки $I_{3}$ в формулах (1) и (2) являются относительными величинами, которые не учитывают потери в оптическом канале, одинаковые для всех комбинаций оптических элементов, такие как отражение от поверхностей оптических элементов и исследуемого образца. Параметр $Q$ учитывает эффективность возбуждения флуоресценции и определяется как

$$
Q=\int I_{\text {д }}(\lambda) T_{\mathrm{H}}(\lambda) S_{\Pi}(\lambda) d \lambda .
$$

Здесь $S_{\text {п }}(\lambda)$ - спектр поглощения красителя RFP. Интегрирование в формулах (1)-(3) проводилось в диапазоне 320-700 nm, который выбран исходя из спектральной чувствительности фотоприемника и спада интенсивности светодиодов более чем на три порядка за пределами данного диапазона. 


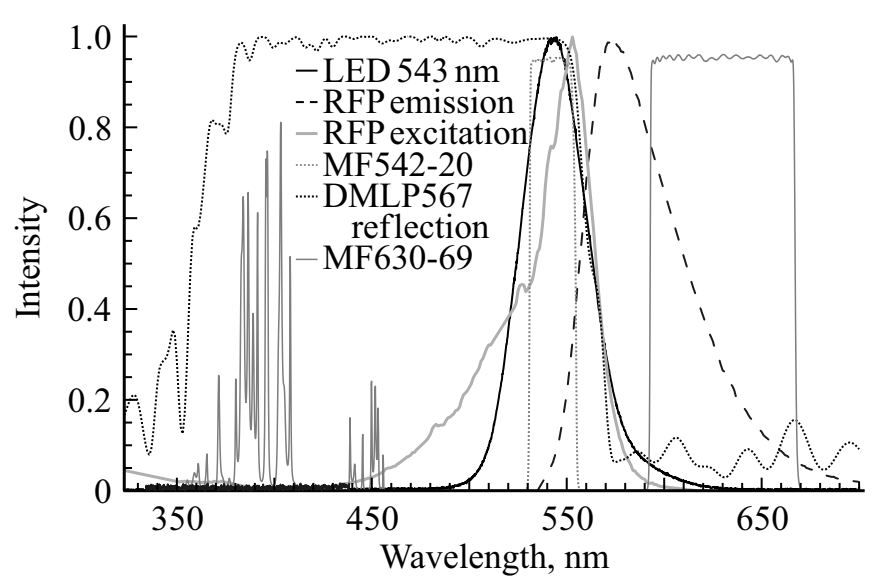

Рис. 2. Спектральные характеристики оптимального набора элементов оптической схемы для детектирования эмиссии RFP.

В табл. 1 представлены расчетные значения параметров $K$ и $Q$ для восьми наборов оптических элементов канала флуоресценции красителя RFP. Параметр $Q$ соответствует относительной эффективности возбуждения флуоресценции. Чем больше параметр $Q$, тем меньшая мощность излучения светодиода требуется для возбуждения определенного количества молекул красителя. Увеличение параметра $Q$ при прочих равных условиях уменьшает уровень засветки фотоприемника возбуждающим излучением и играет немаловажную роль при продолжительном исследовании живых клеток, подверженных фоторазрушению и фототоксикации. Качество изображения во флуоресцентном микроскопе определяется величиной полезного сигнала, динамическим диапазоном матрицы фотоприемника и уровнем засветки. Параметр $K$ прямо пропорционален отношению „сигнал/шум“ и определяет величину полезного сигнала, а следовательно, чувствительность микроскопа и качество флуоресцентного изображения клеток.

Первые шесть строк табл. 1 рассчитаны для диода с длиной волны излучения $543 \mathrm{~nm}$. Видно, что параметр $K$ меняется в несколько раз при смене фильтра на возбуждение (строки 2 и 6 табл. 1) и незначительно изменяется при смене фильтра на эмиссию (строки 1 и 2 табл. 1) при заданных спектрах излучения светодиода и поглощения красителя. В последних двух строчках табл. 1 для сравнения представлены значения параметров $K$ и $Q$ для светодиода с длиной волны $525 \mathrm{~nm}$ для комбинаций фильтров с максимальным значением $K$. Представленные в таблице значения $K$ и $Q$ характерны для конкретного красителя и определенных оптических элементов и показывают, в какой степени их выбор может изменить соотношение полезного сигнала и засветки.

Оптимальная комбинация элементов для диода с длиной волны $543 \mathrm{~nm}$ состоит из фильтра на возбуждение MF542-20, дихроичного зеркала DMLP567 и фильтра на эмиссию MF630-69 (строка 5 табл. 1). Спектральные

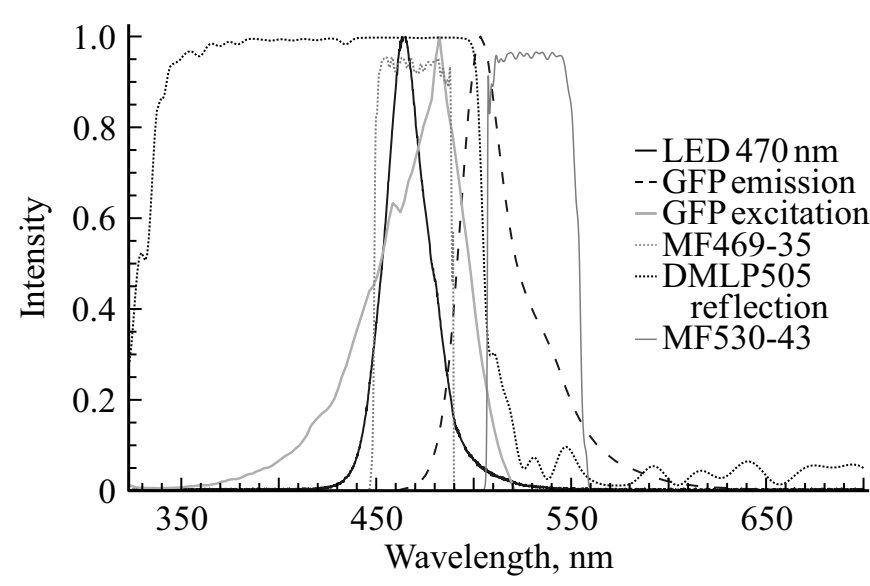

Рис. 3. Спектральные характеристики оптимального набора элементов оптической схемы для детектирования эмиссии GFP.

Таблица 2. Расчетные значения параметров $K$ и $Q$ различных комбинаций фильтров для светодиода $470 \mathrm{~nm}$

\begin{tabular}{l|c|c|c|c}
\hline \multicolumn{1}{c|}{$M_{2}$} & $F_{\text {ex }}$ & $F_{\text {em }}$ & $\begin{array}{c}K \cdot 10^{-7}, \\
\text { arb. units }\end{array}$ & $\begin{array}{c}Q \\
\text { arb. units }\end{array}$ \\
\hline $\begin{array}{l}\text { DMLP505 } \\
\text { MD498 }\end{array}$ & MF469-35 & MF530-43 & 7.84 & 0.04 \\
MF4-35 & MF525-39 & 0.23 & 0.04
\end{tabular}

характеристики такого набора элементов, нормированные на единицу, представлены на рис. 2. Аналогичные расчеты для возбуждающего светодиода с длиной волны $470 \mathrm{~nm}$ показали, что оптимальная комбинация элементов для регистрации флуоресценции красителя GFP состоит из следующих элементов (рис. 3): светодиод LBCPDP-GYHY-35 Osram c центральной длиной волны $470 \mathrm{~nm}$, фильтр на возбуждающее излучение MF469-35, фильтр на эмиссию флуоресценции MF530-43 и дихроичное зеркало DMLP505 (Thorlabs). Следует отметить, что компания Thorlabs для регистрации флуоресценции красителя GFP предлагает использовать фильтр на эмиссию флуоресценции MF525-39 и дихроичное зеркало MD498, что в сочетании со светодиодом LBCPDP-GYHY-35 Osram и фильтром на возбуждающее излучение MF469-35 не является оптимальной комбинацией и проигрывает в 34 раза по значению сигнала люминесценции (табл. 2).

\section{Определение сигналов флуоресценции и засветки фотоприемника излучением накачки}

Приведенные в предыдущем разделе расчеты параметров $K$ и $Q$ показывают, что выбор оптических элементов флуоресцентного микроскопа существенно влияет на сигналы флуоресценции и засветки фотоприемника возбуждающим излучением. Однако выбранные 
параметры показывают лишь относительные величины этих сигналов. На практике качество изображения клеток, получаемое в свете люминесценции красителя, определяется абсолютными величинами этих сигналов. Оценим величины сигналов люминесценции и засветки на матрице фотоприемника на примере красителя GFP. B спецификации матрицы Sony Pregius IMX264 CMOS указано, что темновой ток составляет 3 фотоэлектрона на пиксель. Казалось бы, зная необходимый уровень излучения возбуждения флуоресценции и рассмотренный выше параметр $K$, можно оценить, каким будет уровень засветки на фотоприемнике. Тем не менее это заниженная оценка, так как в расчетах параметра $K$ не учитывались френелевские отражения излучения накачки от оптических элементов, а также лучи накачки, падающие под углом к поверхности фильтра эмиссии, для которых происходит смещение спектральной характеристики фильтра в коротковолновую часть спектра. Такие лучи появляются вследствие отражения накачки от сферических поверхностей оптических элементов и последующего рассеяния. Оценка сигналов флуоресценции и засветки на фотоприемнике проводилась следующим образом. Была измерена плотность мощности излучения возбуждения флуоресценции, при которой возможно подсчитывать и различать клетки одного фенотипа. Она составила примерно $0.0025 \mathrm{~W} / \mathrm{cm}^{2}$, что в 20 раз меньше уровня мощности фоторазрушения и фототоксикации клеток [14,15]. Для сравнения плотность мощности солнечного излучения на поверхности земли в безоблачный день составляет примерно $0.75 \mathrm{~mW} / \mathrm{mm}^{2}$. Далее было рассчитано количество фотонов флуоресценции, достигающих поверхности фотоприемника микроскопа, испускаемых 22000 молекул красителя одной клетки исследуемого образца. В расчетах и эксперименте использовался объектив с числовой апертурой $N A=0.25$. Рассчитанный сигнал флуоресценции от одной клетки составил 262 фотона в секунду. В расчетах использовались данные для красителя GFP по квантовому выходу флуоресценции, равному 0.53 , и коэффициенту экстинкции, равному $700001 \mathrm{M}^{-1} \mathrm{~cm}^{-1}$ [16]. Принимая во внимание, что размер изображения одной клетки на матрице фотоприемника составляет $13.4 \mu \mathrm{m}^{2}$, можно определить, что на один пиксель матрицы фотоприемника размером $3.45 \times 3.45 \mu \mathrm{m}$ приходится примерно 250 фотонов излучения флуоресценции. Полученное значение полезного сигнала значительно превышает темновое и лежит на линейном участке динамического диапазона фотоприемника при специфицируемом токе насыщения матрицы фотоприемника Sony Pregius IMX264 CMOS 10000 фотоэлектронов на пиксель.

Оценка засветки излучением накачки на матрице фотоприемника проводилась следующим образом. Была измерена плотность мощности излучения накачки на длине волны $470 \mathrm{~nm}$ в плоскости фотоприемника в микроскопе без фильтра на эмиссию излучения флуоресценции MF530-43, которая составила $0.0016 \mathrm{~mW} / \mathrm{cm}^{2}$.

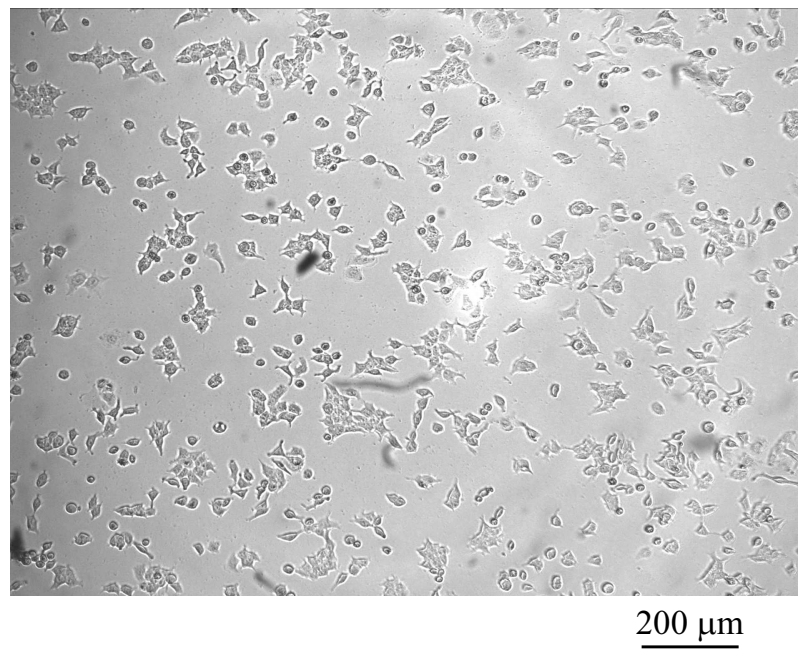

Рис. 4. Изображение клеток в проходящем свете от белого диода.

Коэффициент пропускания фильтра MF530-43 на данной длине волны составляет $13.04 \cdot 10^{-6 \%}$. Это означает, что засветка одного пикселя матрицы фотоприемника составляет 0.35 фотона. Полученная расчетная величина на порядок меньше темнового тока матрицы и не учитывает вклад рассеянных и отраженных от объектива и образца фотонов, падающих под различными углами на фильтр эмиссии. То есть уровень засветки фотоприемника может быть сравнимым или превышать уровень темнового тока при работе с клетками с меньшей концентрацией флуоресцентного белка, а следовательно, важно учитывать параметр $K$ при выборе оптических элементов флуоресцентного микроскопа. Он может играть важную роль для получения максимальной чувствительности при регистрации флуоресценции красителя при низкой концентрации.

\section{Регистрация флуоресценции клеток}

Клетки линий SH-SY5Y и HEK-293, содержащие репортерные системы для регистрации экспрессии маркеров эпителиального (Е-кадгерин) и мезенхимального (N-кадгерин) состояний клеток (CDH1-TurboGFP и CDH2-TurboRFP соответственно), культивировали в культуральных флаконах с площадью поверхности $25 \mathrm{~cm}^{2}$ в $5 \mathrm{ml}$ среды DMEM (Gibco, CША) с добавлением $10 \%$ фетальной бычьей сыворотки (HyClone, Thermo Scientific, США) и $0.1 \%$ пенициллин/стрептомицина (Gibco, США) как описано в [17].

Перед проведением измерений клетки помещали в 96-луночные планшеты. Экспрессию флуоресцентных белков, контролируемую участками промоторов CDH1 и $\mathrm{CDH} 2$, регистрировали с помощью флуоресцентного устройства на длинах волн 470 и $543 \mathrm{~nm}$. Плотность мощности излучения на длине волны $543 \mathrm{~nm}$ возбуждающего флуоресценцию красителя RFP составляет 


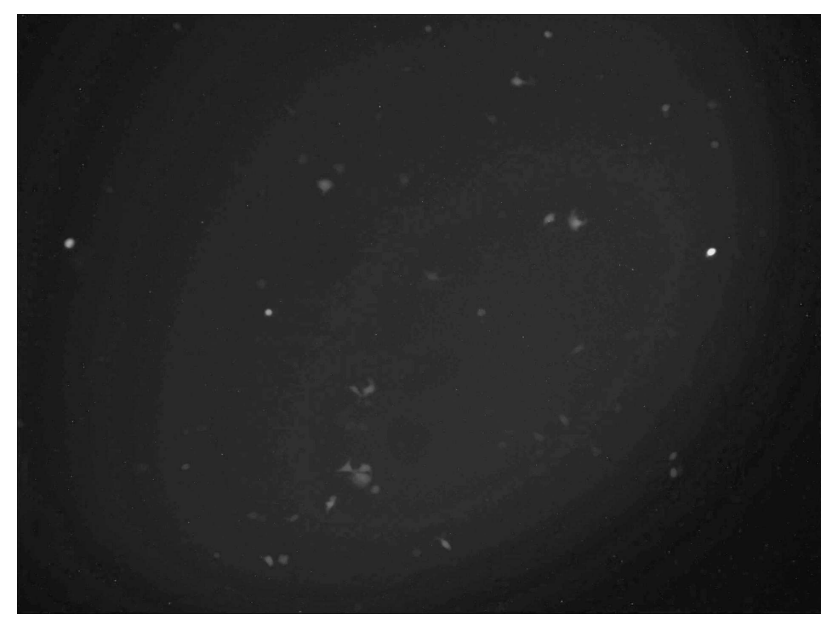

$200 \mu \mathrm{m}$

Pис. 5. Изображение клеток, экспрессирующих GFP.

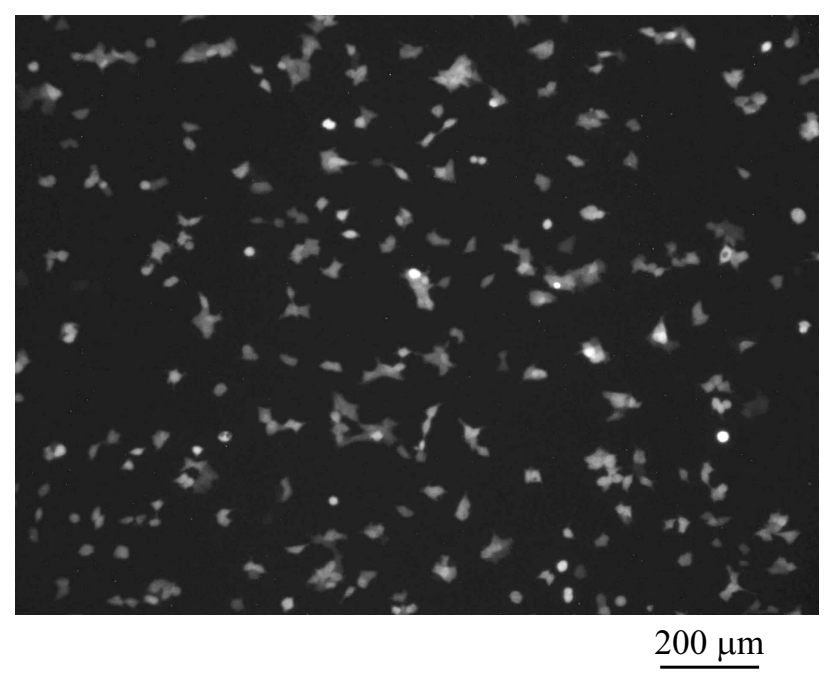

Рис. 6. Изображение клеток, экспрессирующих RFP.

$0.0045 \mathrm{~W} / \mathrm{cm}^{2}$, плотность мощности излучения на длине волны $470 \mathrm{~nm}$ возбуждающего флуоресценцию красителя GFP составляет $0.0025 \mathrm{~W} / \mathrm{cm}^{2}$, плотность мощности белого светодиода, формирующего изображение в проходящем свете, составляет $0.025 \mathrm{~mW} / \mathrm{mm}^{2}$. Полученные изображения представлены на рис. 4-6.

\section{Заключение}

Создан флуоресцентный микроскоп, предназначенный для проведения исследований процесса ЭМТ в термостатированном биочипе в режиме реального времени по регистрации флуоресценции белков GFP и RFP. Введены параметры $K$ и $Q$, определяющие относительные величины сигналов люминесценции и засветки фотоприемника возбуждающим излучением, позволяющие сравнивать различные комбинации стандартных, коммерчески доступных элементов оптической системы микроскопа. Введенные параметры упрощают выбор оптимального набора элементов с минимальным уровнем возбуждающего излучения и минимальной засветкой фотоприемника при максимальном сигнале флуоресценции и могут быть использованы при разработке люминесцентного микроскопа, предназначенного для работы с другими красителями.

Полученная система может быть использована для высокопроизводительного поиска потенциальных противоопухолевых лекарственных средств, мишенями которых будут являться определенные стадии каскада метастазирования.

Работа выполнена при поддержке ФЦП „Исследования и разработки по приоритетным направлениям развития научно-технологического комплекса России на 2014-2020 годы“ (УИПНИ RFMEFI61316Х0058).

\section{Список литературы}

[1] Dixit R., Cyr R. // Plant J. 2003. V. 36. P. 280-290. doi 10.1046/j.1365-313X.2003.01868.x

[2] Schneckenburger H., Weber P., Wagner M., Bruns T., Richte V., Schickinger S., Wittig R. // Photonics \& Lasers in Medicine. 2012. V. 1. N 1. P. 35-40. doi 10.1515/plm2011-0011

[3] Frigault M.M., Lacoste J., Swift J.L., Brown C.M. // J. Cell Sci. 2009. V. 122. P. 753-767. doi 10.1242/jcs.033837

[4] Masters B.R., Peter T.C.So. // Optics Express. 2001. V. 8. N 1. P. 2-10. doi 10.1364/OE.8.000002

[5] Tsai M.R., Chen S.Y., Shieh D.B., Lou P.J., Sun C.K. // Biomed. Opt. Express. 2011. V. 2. N 8. P. 2317-2328. doi 10.1364/BOE.2.002317

[6] Доронина-Амитонова Л.В., Федотов И.В., Федотов А.Б., Анохин К.В., Желтиков А.М. // УФН. 2015. Т. 184. № 4. C. 371-392. doi 10.3367/UFNr.0185.201504c.0371

[7] Pires N.M.M., Dong T., Hanke U., Hoivik N. // Sensors. 2014. V. 14. P. $15458-15479$. doi $10.3390 / \mathrm{s} 140815458$

[8] Samatov T.R., Shkurnikov M.U., Tonevitskaya S.A. Tonevitsky A.G. // Progr. histochem. cytochem. 2015. V. 49. N 4. P. 21-29. doi 10.1016/j.proghi.2015.01.001

[9] Wiedenmann J., Oswald F., Nienhaus G.U. // Life. 2009. V. 61. P. 1029-1042. doi 10.1002/iub.256

[10] Chudakov D.M., Matz M.V., Lukyanov S., Lukyanov K.A. // Physiol. Rev. 2010. V. 90. P. 1103-1163. doi 10.1152/physrev.00038.2009

[11] [Электронный ресурс]. Режим доступа: http://www.stormoff.ru/fluorescentnaya-mikroskopiya1/

[12] [Электронный ресурс ]. Режим доступа: http://www.biocompare.com/pfu/10242895/soids/2254335/ /Microscopes_and_Cell_Imaging_Systems/ /Live_Cell_Imaging?vmpi_6408=1

[13] Gautam P., Recino A., Foale R.D., Zhao J., Gan S.U., Wallberg M., Calne R., Lever A. // J. Gene Medicine. 2016. V. 18. P. 312-321. doi 10.1002/jgm.2900 
[14] Schneckenburger H., Weber P., Wagner M., Schickinger S., Richter V., Bruns T., Strauss W.S.L., Witting R. // J. Microscopy. 2012. V. 245. P. 311-318.

doi 10.1111/j.1365-2818.2011.03576.x

[15] Schilling Z., Frank E., Magidson V., Wason J., Lončarek J., Boyer K., Wen J., Khodjakov A. // J. Microsc. 2012. V. 246. P. 160-167. doi 10.1111/j.1365-2818.2012.03605.x

[16] [Электронный ресурс]. Режим доступа: http://evrogen.ru/protein-descriptions/TurboGFPdescription.pdf

[17] Poloznikov A.A., Zakhariants A.A., Nikulin S.V., Smirnova N.A., Hushpulian D.M., Gaisina I.N., Tonevitsky A.G., Tishkov V.I., Gazaryan I.G. // Biochimie. 2016. V. 133. P. 74-79. doi 10.1016/j.biochi.2016.12.004 